\title{
Does Silent Giardia Infection Need Any Attention?
}

\author{
Supaluk Popruk ${ }^{*}, 1$, Kanthinich Thima ${ }^{1}$, Ruenruetai Udonsom ${ }^{1}$, Pongruj Rattaprasert ${ }^{1}$ and \\ Yaowalark Sukthana ${ }^{1,2}$
}

\author{
${ }^{I}$ Department of Protozoology, Faculty of Tropical Medicine, Mahidol University, Bangkok, Thailand \\ ${ }^{2}$ Mahidol University International College, Mahidol University, Nakhon Pathom, Thailand
}

\begin{abstract}
Even though treatment of symptomatic cases as well as improving hygiene and sanitation conditions decrease giardiasis in underdeveloped and/or developing countries, Giardia duodenalis infection is still frequently encountered especially in children living in crowded conditions leading to public health problems. We studied the prevalence of $G$. duodenalis infection in 274 asymptomatic Thai boy orphans, living in/around the Bangkok metropolitan area, by use of direct fecal smear and formalin-ethyl acetate techniques. This was done to explore our hypothesis that children with asymptomatic giardiasis, who are not likely to be treated, have a high potential for spreading this pathogen. Positive Giardia cases were further genotyped by 2 genes: small subunit ribosomal RNA ( $s r R N A)$ and glutamate dehydrogenase $(g d h)$ to determine the distribution of each $G$. duodenalis assemblage. Positive G. duodenalis infection was $11.67 \%$ and revealed at $10.63 \%, 12 \%$ and $15 \%$, in PK, TMK, and MHK orphanages, respectively. The overall parasitic infection, including Giardia, was 48.54\% consisting mostly of non-pathogenic organisms i.e. Blastocystis hominis, Entamoeba coli, Endolimax nana, Entamoeba histolytica-like, Chilomastix mesnili, Trichuris trichiura, Hymenolepis nana, Strongyloides stercoralis and Hookworm. Fourteen (70 \%) and $4(20 \%)$ out of the 20 positive Giardia samples could be amplified by ssrRNA and $g d h$ genes, respectively; three belonged to the sub-assemblage BIV and only one indicated sub-assemblage AII. Thus children infected with sub-assemblage BIV isolate are more common in this study. In conclusion, we focused on asymptomatic giardiasis children, hitherto unrecognized, who consistently contaminate their environments with cysts. We favor not only treating these children to eradicate the source of the infection, but also to encourage an active surveillance program consisting of highly sensitive methods to identify silent giardiasis cases. In addition to these 2 strategies, a continuous fruitful health education program for all stakeholders is another crucial tool. These actions will benefit the control of human giardiasis and reduce public health problems.
\end{abstract}

Keywords: Giardia duodenalis, asymptomatic Thai boy orphans, genotype, small subunit ribosomal RNA, glutamate dehydrogenase.

\section{INTRODUCTION}

Giardia duodenalis is the most frequent intestinal protozoa found throughout the world [1]. Most infections result from fecal-oral transmission by ingestion of contaminated water and food which are the major vehicles for transmitting the infection [2,3]. G. duodenalis is clearly associated with children living in crowded conditions, such as in childcare centers or orphanages. Moreover, this protozoan eventually produces intermittent and chronic gastrointestinal symptoms leading to public health problems [4,5]. Children infected with $G$. duodenalis are irritable and have behavioral problems. They fail to thrive and suffer growth failure because of malabsorption [6]. Asymptomatic infected children, who do not demonstrate any obvious clinical signs and symptoms, persistently contaminate their environment by shedding cysts and thus unknowingly transmitting G. duodenalis to new hosts.

In Thailand, giardiasis is still a significant problem in children. The rate of $G$. duodenalis infection depends on the

*Address correspondence to this author at the Department of Protozoology, Faculty of Tropical Medicine, Mahidol University, 420/6 Ratchawithi Road, Rajthevee, Bangkok 10400, Thailand; Tel: 66-(0)-2354-9100, ext. 1830; Fax: 66-(0)-2643-5601; E-mail: tmspo@mahidol.ac.th children's age, their level of personal hygiene, and local sanitary conditions [7]. Several studies show a continued high prevalence of giardiasis in Thailand [8-10]. Saksirisampant et al reported a high prevalence of human giardiasis in preschool orphans as well as in pre-school children aged 3 months to 5 years in rural areas of Thailand $[11,12]$. Some children carry $G$. duodenalis, but they are asymptomatic. These carriers have a high potential for spreading this pathogen making the situation worse in at-risk areas.

G. duodenalis is comprised of at least 7 assemblages: A, $\mathrm{B}, \mathrm{C}, \mathrm{D}, \mathrm{E}, \mathrm{F}$ and $\mathrm{G}$ [13] but only assemblages A (AI, AII) and $\mathrm{B}$ (BIII, BIV) have been recovered from human [14]. Metabolism and growth rate may be the important factors in regulating phenotypic differences between assemblages A and $\mathrm{B}$. It may be suggested that there are differences in the nature of infection between assemblages A and B, including duration of infection, drug sensitivity and virulence [15]. Amar and colleagues reported that children infected with assemblage A isolates had greater diarrheal symptoms than children infected with assemblage B isolates [16]. Children infected with assemblage B isolates easily spread $G$. duodenalis cysts in communities by unknowingly shedding them. In this study, we examined asymptomatic Thai boy orphans living in 3 orphanages located in/around Bangkok in order to investigate $G$. duodenalis and other intestinal 
parasitic infections. Genotyping $G$. duodenalis in positive stool samples was carried out to determine the distribution in each $G$. duodenalis assemblage. We believe that the obtained data can provide significant insight into $G$. duodenalis infection, and thus effective strategies for the prevention and treatment of giardiasis, especially in crowded conditions, will be administered.

\section{MATERIALS AND METHODS}

\section{Study Subjects}

Two hundred and seventy-four Thai boy orphans from 3 orphanages (PK, MHK and TMK), located in/around Bangkok, were enrolled in the study from August to December 2009. The subjects ranged in age from 5-15 years and were comprised of 94, 100 and 80 children from PK, MHK and TMK homes, respectively. All participants were asymptomatic and healthy at the time of the study.

\section{Ethical Approval}

The study protocol was approved by the Ethics Committee of the Faculty of Tropical Medicine, Mahidol University, Bangkok, Thailand (MUTM 2009-032-01). Written informed consents were obtained from all participants and from the guardians of THE children before stool samples were collected.

\section{Stool Sample Collection}

A verbal explanation and specific instructions for sampling and avoidable contamination of the stool samples were given to all the children and guardians. Fresh stool samples were collected in the early morning and transported in proper conditions to the laboratory for microscopic examination at the Department of Protozoology, Faculty of Tropical Medicine, Mahidol University.

All stool samples were examined by direct fecal smear and formalin-ethyl acetate techniques. The presence of intestinal parasites was investigated by two independent well-trained microscopists. Positive cysts, trophozoites, eggs or larvae were identified based on diagnostic criteria of shape, size, color and special characters of those intestinal parasites according to the Atlas of medical parasitology: with 465 colour illustrations [17]. All the positive stool samples for $G$. duodenalis were genotyped and sub-genotyped.

\section{DNA Extraction and Genotyping}

DNA was extracted from all the $G$. duodenalis positive samples using a Flexi Gene DNA kit (Qiagen, Hilden, Germany). Unfortunately, some $G$. duodenalis positive stool samples were too small to extract, therefore we excluded them. All together there were 20 stool samples for DNA extraction. DNA samples were stored at $-20^{\circ} \mathrm{C}$ until further use.

Genomic DNA was amplified by PCR using the specific pairs of oligonucleotide primers. Twenty positive samples of $G$. duodenalis were genotyped by 2 genes: small subunit ribosomal RNA (ssrRNA) gene and glutamate dehydrogenase $(g d h)$ gene. The $s s r R N A$ gene provides screening in all assemblages of $G$. duodenalis infection, whilst the $g d h$ gene is useful for grouping them into their genetic assemblages and also into sub-assemblages AI, AII, BIII and $\mathrm{BIV}$. The single-round 117- bp PCR product of $s s r R N A$ gene was amplified by forward primer NewGiarF ( $5^{\prime}$-ACG CTC TCC CCA AGG ACG-3') and reverse primer NewGiarR (5' GGT TGC CAG CGG TGT CC-3'). PCR reactions were performed on total volumes of $50 \mu \mathrm{L}$ using $2.5 \mu \mathrm{l}$ of genomic DNA template, $300 \mathrm{nM}$ of each oligonucleotide primer, $200 \mu \mathrm{M}$ of dNTPs (dATP, dCTP, dGTP, dTTP), PCR buffer $10 \mathrm{mM}$ Tris- $\mathrm{HCl}(\mathrm{pH} 8.3), 50 \mathrm{mM}$ of $\mathrm{KCl}$, $1.5 \mathrm{mM}$ of $\mathrm{MgCl}_{2}, 1.0 \mathrm{U}$ of Taq polymerase. DNA amplification was performed in a Gene Amp PCR system 9700 programmed (Applied Biosystem, USA) and carried out at $95^{\circ} \mathrm{C}$ for $5 \mathrm{~min}$, followed by 35 cycles in which each cycle took 30 seconds at $95{ }^{\circ} \mathrm{C}$ denature, 30 seconds at $58^{\circ} \mathrm{C}$ annealing temperature, and 30 seconds at $72^{\circ} \mathrm{C}$ extension, and a final extension step of $72^{\circ} \mathrm{C}$ for $4 \mathrm{~min}$. For the seminested PCR, the 432- bp PCR product of $g d h$ gene was amplified by external forward primer GDHeF (5'-TCA ACG TAA AGC GAG GAT TCC GT-3'), internal forward primer GDHiF: (5'- CAG TAC ACC TCA GCT CTC GG-3') and reverse primer GDHiR (5'- GTT CTC CTT GCA CAT CTC C-3') [18], respectively.

\section{Restriction Fragment Length Polymorphism (RFLP) Analysis}

The 432 bp PCR product of $g d h$ gene was digested with $10 \mathrm{U}$ of $\mathrm{NlaIV}$ for 3 hours at $37^{\circ} \mathrm{C}$ or $5 \mathrm{U}$ of RsaI for 3 hours at $37^{\circ} \mathrm{C}$. The NlaIV restriction enzyme can digest $432 \mathrm{bp}$ PCR products which restriction digest fragments can distinguish between sub-assemblages AI and AII, and assemblage B. Diagnostic genotyping profile (bp) of $G$. duodenalis among assemblages when digested by NlaIV was as follows: 90, 120, 150 (AI); 70, 80, 90, 120 (AII); 120, 290 (B), respectively. Additionally, RsaI digestion restriction enzyme distinguished between sub-assemblage BIII and BIV. Diagnostic genotyping profile (bp) of G. duodenalis distinguished between assemblage $\mathrm{A}$, sub-assemblages BIII and BIV was as follows: 280, 130 (A); 130, 300 (BIII); 430 (BIV), respectively. The restriction digest fragments were separated on $3.0 \%$ agarose gel, stained with ethidium bromide to visualize the different genotypes, and measured for fragment size by reference to a $50 \mathrm{bp}$ DNA ladder marker. Moreover, the $432 \mathrm{bp}$ PCR products of $g d h$ gene were sequenced to confirm RFLP analysis as well.

\section{Statistical Analysis}

Descriptive analysis was used with percentages to express the prevalence of $G$. duodenalis and other intestinal parasitic infections

\section{RESULTS}

The overall prevalence of intestinal parasitic infection in 274 Thai boy orphans was $133(48.54 \%)$, and there were 34 cases of Giardia infection (12.41\%). The highest prevalence was found at MHK home with an infection rate of $53.75 \%$ compared with $46.73 \%$ and $46 \%$ AT PK and TMK homes, respectively (Fig. 1). One or more intestinal parasites were observed in all 3 orphanages. The prevalence of single 


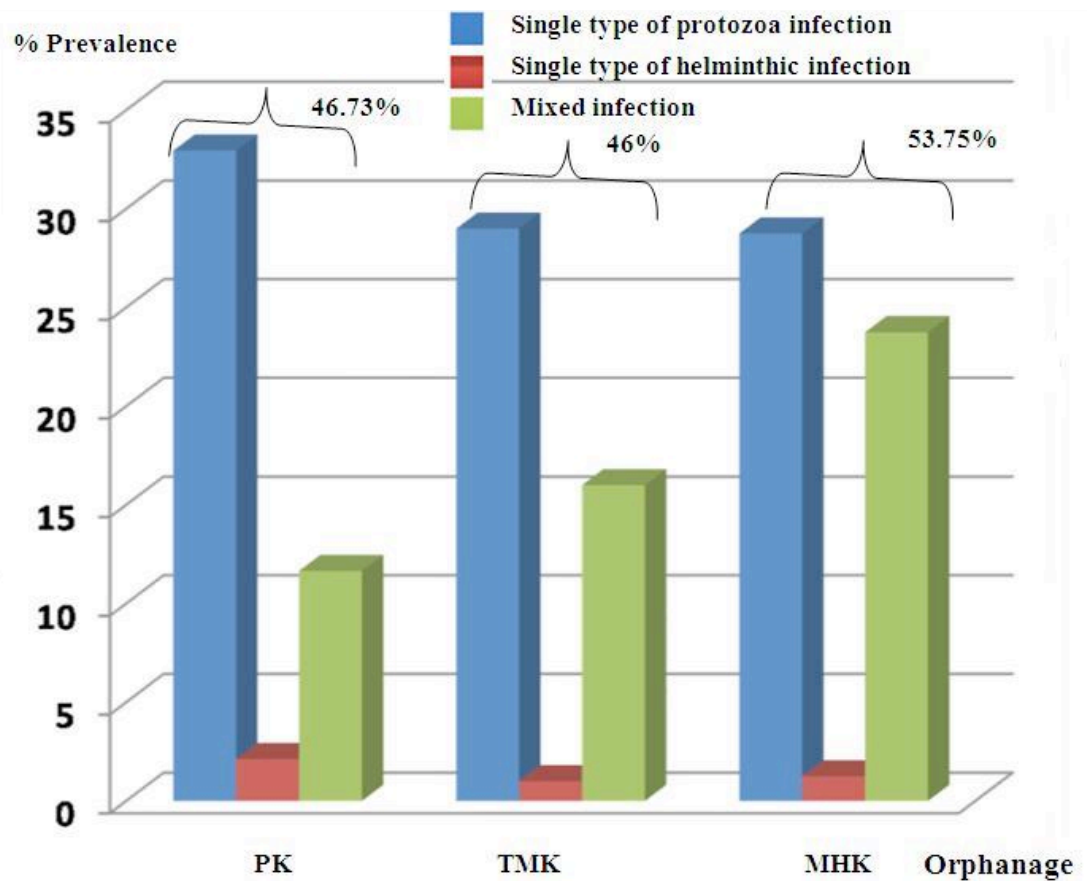

Fig. (1). Prevalence of intestinal parasitic infections classified by orphanages (PK, TMK and MHK, respectively). Overall intestinal parasitic infection was 133 (48.54\%) out of 274 cases. Note that protozoa infection was much higher than helminthic infection.

protozoa infection was much higher than helminthes in all 3 orphanages (Fig. 1).

There were single and mixed intestinal parasitic infections in this study as shown in Table 1. However, the prominent one was a single infection presented at 33 (35.07\%), 30 $(30 \%)$ and $24(30 \%)$ cases in PK, TMK and MHK homes, whereas mixed infections were $11(11.66 \%), 16(16 \%)$ and $19(23.75 \%)$ cases in PK, TMK and MHK homes, respectively. When focusing only on protozoa, infected children with a single infection of protozoa were 31 (32.95\%), 29 (29\%) and $23(28.75 \%)$ cases in PK, TMK and MHK homes, and helminthes were $2(2.12 \%), 1(1 \%)$ and $1(1.25 \%)$ cases in PK, TMK and MHK homes, respectively. The prevalence of $G$. duodenalis infection in PK, TMK, and MHK homes was $10.63 \%, 12 \%$ and $15 \%$, respectively (Fig. 2). Children living in MHK home demonstrated the highest prevalence of $G$. duodenalis. Other intestinal parasites included Blastocystis hominis, Entamoeba coli, Endolimax nana, Entamoeba histolytica-like, Chilomastix mesnili, Trichuris trichiura, Hymenolepis nana, Strongyloides stercoralis and Hookworm. The most frequent protozoa found in this study were G. duodenalis and B. hominis.

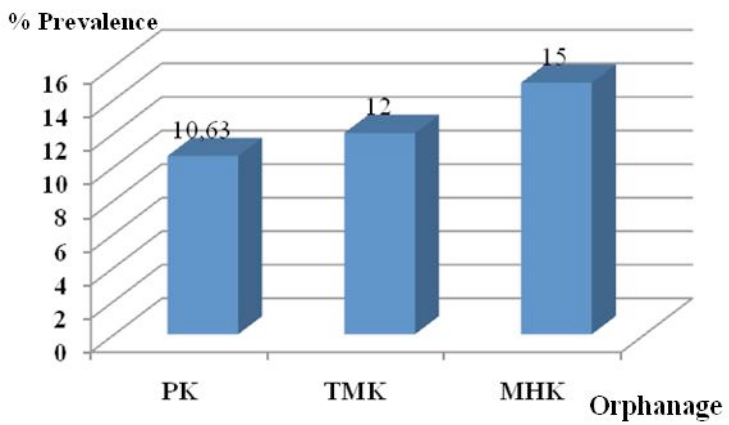

Fig. (2). Prevalence of Giardia duodenalis infection classified by orphanages (PK, TMK and MHK, respectively).
There were 14 out of 20 Giardia positive stool samples amplified by the 117 bp ssrRNA PCR products (Fig. 3), while $4(20 \%)$ were positive by the 432 bp $g d h$ PCR products (Fig. 4A).

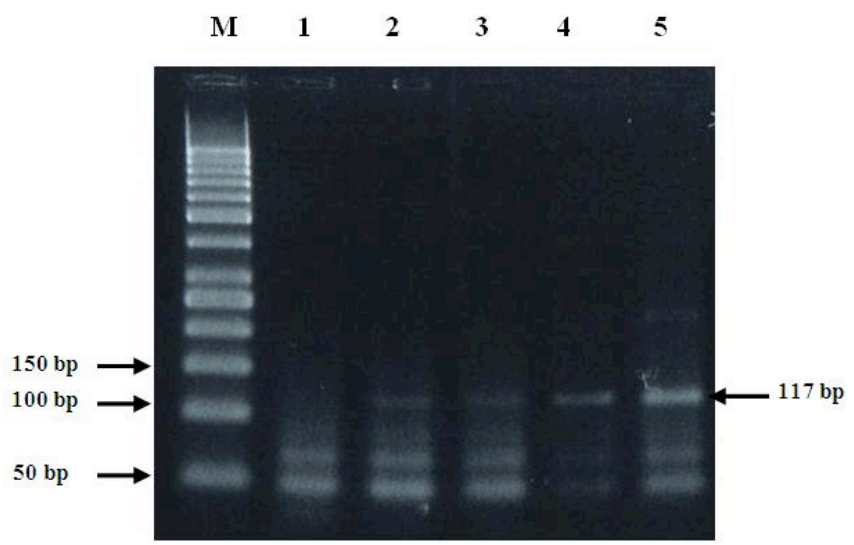

Fig. (3). 117 bp PCR products of ssrRNA gene of Giardia duodenalis. Lane M: 50 -bp ladder; lane 1: Negative control; lane 2-4: Positive unknown samples; lane 5: Positive control.

The 4 positive stool samples of 432 bp PCR products of $g d h$ gene were digested with Nla IV and we found one stool sample that indicated sub-assemblage AII; which showed a diagnostic genotyping profile (bp) as follows: 70, 80, 90, 120 (Fig. 4B, unknown sample No. 1). The remaining three stool samples belonged to the assemblages B, and showed a diagnostic genotyping profile (bp) as follows: 120 and 290, respectively (Fig. 4B, unknown sample No. 2-4). Assemblage B was then further distinguished by $R s a$ I endonuclease into two sub-assemblages BIII and BIV. The predicted restriction fragment pattern showed that the remaining three stool samples indicated sub-assemblage BIV, diagnostic 
Table 1. Type of Intestinal Parasites Detected in 274 Thai Boy Orphans in 3 Orphanages

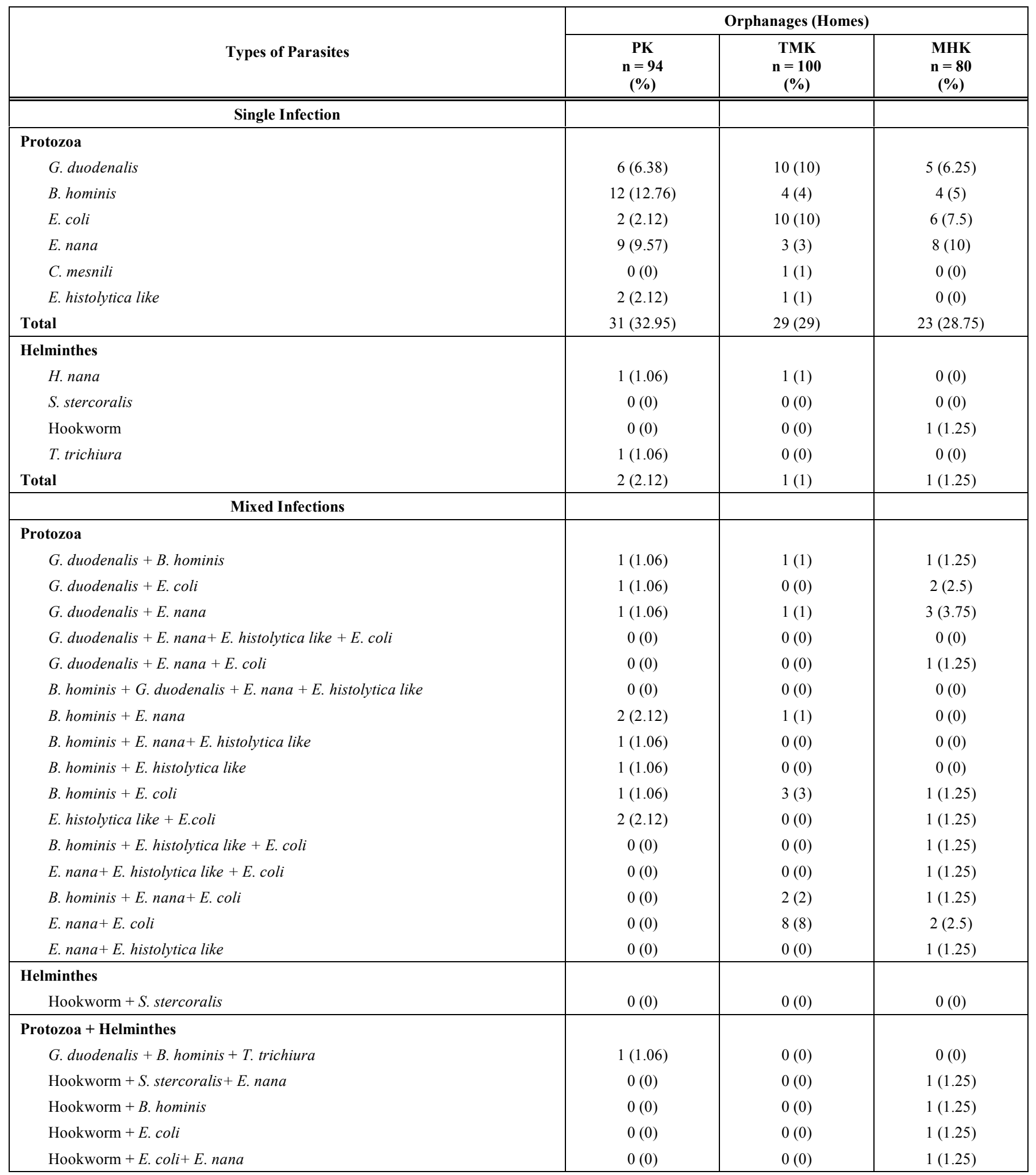

genotyping profile (bp) was as follows: 430 (BIV). Moreover, the sequencing analysis was confirmed the RFLP analysis (data not shown).

\section{DISCUSSION}

The findings in our study confirmed previous existing reports in Thailand [19-21], which show a high prevalence of 

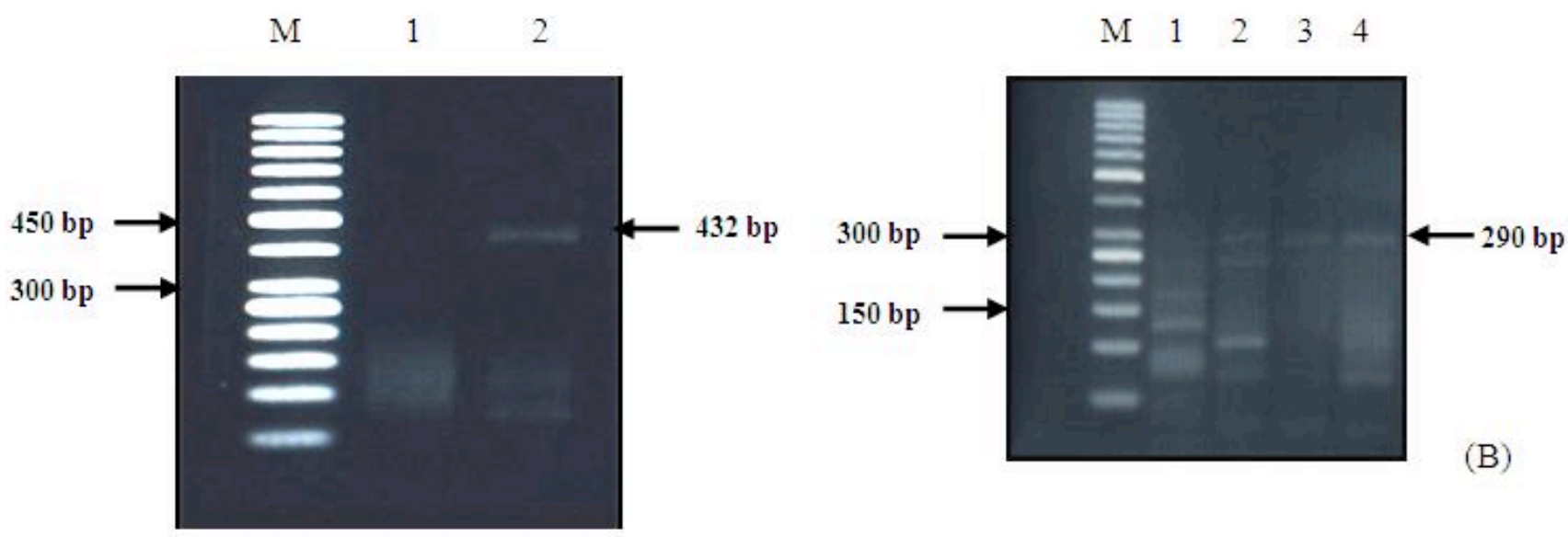

(A)

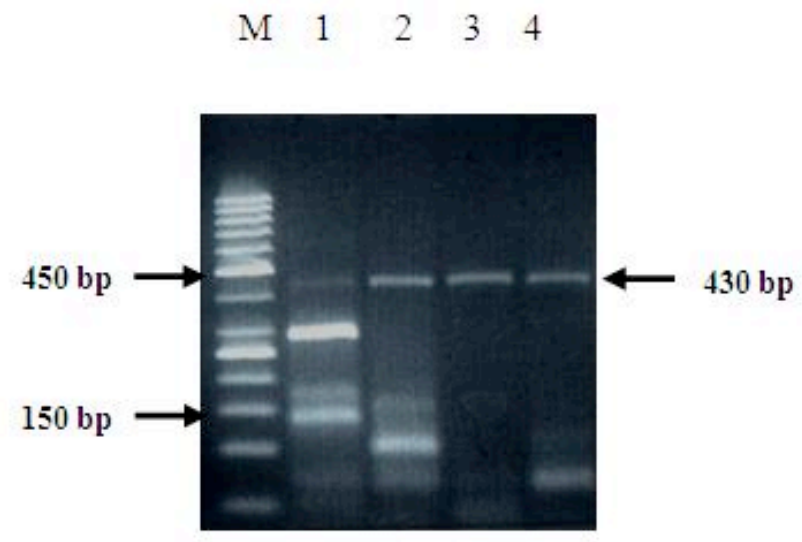

(C)

Fig. (4). PCR products of $g d h$ gene of G. duodenalis. (A) Lane M: 50 -bp ladder; lane 1: Negative control; lane 2: G. duodenalis positive control. (B) RFLP analysis for 432 bp PCR products of $g d h$ gene digested with the Nla IV. Lane M: 50 -bp ladder; lane 1-4, Unknown samples (1= Sub-assemblage AII, 2-4 = Assemblages B). (C) RFLP analysis for $432 \mathrm{bp} \mathrm{PCR} \mathrm{products} \mathrm{of} g d h$ gene digested with the Rsa I. Lane M: 50 -bp ladder; lane 1-4: Unknown samples. (1= Sub-assemblage AII, 2-4 = Sub-assemblage BIV).

intestinal parasitic infections. When focusing only on protozoa, especially Giardia and Blastocystis infections, they clearly show a higher infection rate than helminthes (Table 1). An improvement in personal hygiene, better sanitation and a widespread health education campaign have reduced helminthic infections, but protozoa are still present even in asymptomatic hosts. If attention is focused on pathogenic organisms, G. duodenalis predominates. Clinical presentations of giardiasis vary from asymptomatic carriage to acute and chronic diarrhea. Our study samples were healthy and usually needed no treatment. However, about half of asymptomatic Giardia-infected children excreted cysts for more than six months [22]. Therefore, they were potential carriers who could spread pathogens, including Giardia, to other persons in orphanages or communities while unaware that they were doing so. This is one explanation of why giardiasis is still prevalent worldwide and difficult to control.

The various prevalence of giardiasis in each area depends on personal and community hygiene. In general, giardiasis is more common in the developing world than in developed countries. Findings in stool specimens suggest the prevalence of Giardia duodenalis in the developing world was $20-30 \%$, while in the industrialized world IT was 2-5\% [4]. It is more common in children living in orphanages than those in day care centers $(41.4 \%$ vs. $3.7 \%)$ [23]. In the present study, the prevalence of giardiasis in MHK home was higher than PK and TMH home. This might be because the MHK orphanage is located in a rural area, thus children living in this orphanage were closer to contaminated environments that served as potential sources of $G$. duodenalis. The other two orphanages are in urban locations that have better sanitation and where better standards of personal hygiene are practiced.

There are two major assemblages, including $\mathrm{A}$ and $\mathrm{B}$, which can be recovered from human subjects whereas the assemblages $C$ to $G$ are specifically found in other mammalian hosts [24]. Sub-assemblage AI is commonly found in zoonotic pathogens, whereas sub-assemblage AII is restricted to humans. Furthermore, assemblage B appears to be human-specific [2]. The correlation between human clinical giardisis and genotypes has been explored by many researchers. However, results were inconclusive. A study from Egypt denied any correlation between G. duodenalis genotype and clinical presentation [25]. Studies from Bangladesh, Peru and Spain showed a relationship between assemblage A, both sub-assemblages AI and AII, and diarrheal symptoms, while Assemblage B was found in asymptomatic hosts [26-28]. However, symptomatic giardiasis 
related to Assemblage B was also demonstrated by studies from Saudi Arabia and Cuba [29, 30]. Children with subassemblage AII alone, or mixed infections with assemblage $\mathrm{B}$, had diarrhea significantly more frequently $(\mathrm{P}=0.07)$. In our study, children infected with sub-assemblage BIV isolate are more common and asymptomatic. Yet their treatment is neglected, leading to nutritional disorders and poor growth. Moreover, they easily spread G. duodenalis cysts in their environments.

We used ssrRNA and $g d h$ genes for screening and genotyping $G$. duodenalis. The ssrRNA gene has high copy numbers arranged in tandem repeats as well as a more conserved sequence [31]. For these reasons, it is commonly used for screening Giardia infection in populations. Furthermore, the $g d h$ gene was used on the basis of being able to differentiate genetic assemblages using NlaIV and $R s a \mathrm{I}$ endonuclease enzymes in PCR-RFLP analysis [27].

In asymptomatic orphans, we found sub-assemblage BIV more often than Assemblage A. However, the sample was too small and could not be amplified. Our findings revealed the same direction as Ratanapo and colleagues' study which was carried out in a different setting: school pupils in rural communities in Thailand [32]. Silent giardiasis children have no obvious symptoms, but they are still shedding cysts in their stool and are the source of infection in their immediate environment.

We, therefore, favor treating asymptomatic cyst passers so as to get rid of a potential source of infection in communities. Actively identifying silent giardiasis cases using highly sensitive tools is another important strategy. In addition, instruction in personnel hygiene and good sanitation along with proper health education in parasitic prevention should be continuously given to guardians and children. The benefits of these actions will be the control of human giardiasis and a reduction in public health problems.

\section{ACKNOWLEDGEMENTS}

We would like to thank all the guardians and volunteers in 3 Thai orphanages, and the staffs of the Department of Protozoology and the Faculty of Tropical Medicine at Mahidol University for their help in collecting stool samples. This study was supported by a Research Grant from the Faculty of Tropical Medicine, Mahidol University, year 2009.

\section{CONFLICT OF INTEREST}

None Declared.

\section{REFERENCES}

[1] Caccio SM, Thompson RC, McLauchlin J, Smith HV. Unravelling Cryptosporidium and Giardia epidemiology. Trends Parasitol 2005; 21: 430-7.

[2] Almeida AA, Delgado ML, Soares SC, et al. Genotype analysis of Giardia isolated from asymptomatic children in northern Portugal. J Eukaryot Microbiol 2006; 53: S177-8.

[3] Adam RD. Biology of Giardia lamblia. Clin Microbiol Rev 2001; 14: 447-75.

[4] Ortega YR, Adam RD. Giardia: overview and update. Clin Infect Dis 1997; 25: 545-9.
[5] Farthing MJ. Giardiasis. Gastroenterol Clin North Am 1996; 25 : 493-515.

[6] Fraser D, Bilenko N, Deckelbaum RJ, Dagan R, El-On J, Naggan L. Giardia lamblia carriage in Israeli Bedouin infants: risk factors and consequences. Clin Infect Dis 2000; 30: 419-24.

[7] Stuart JM, Orr HJ, Warburton FG, et al. Risk factors for sporadic giardiasis: a case-control study in southwestern England. Emerg Infect Dis 2003; 9: 229-33.

[8] Waikagul J, Krudsood S, Radomyos P, et al. A cross-sectional study of intestinal parasitic infections among schoolchildren in Nan Province, Northern Thailand. Southeast Asian J Trop Med Public Health 2002; 33: 218-23.

[9] Sirivichayakul C, Pojjaroen-anant C, Wisetsing P, Siripanth C, Chanthavanich P, Pengsaa K. Prevalence of intestinal parasitic infection among Thai people with mental handicaps. Southeast Asian J Trop Med Public Health 2003; 34: 259-63.

[10] Mungthin M, Suwannasaeng R, Naaglor T, Areekul W, Leelayoova S. Asymptomatic intestinal microsporidiosis in Thai orphans and child-care workers. Trans R Soc Trop Med Hyg 2001; 95: 304-6.

[11] Saksirisampant W, Nuchprayoon S, Wiwanitkit V, Yenthakam S, Ampavasiri A. Intestinal parasitic infestations among children in an orphanage in Pathum Thani province. J Med Assoc Thai 2003; 86: S263-70.

[12] Wongstitwilairoong B, Srijan A, Serichantalergs O, et al. Intestinal parasitic infections among pre-school children in Sangkhlaburi, Thailand. Am J Trop Med Hyg 2007; 76: 345-50.

[13] Volotao AC, Costa-Macedo LM, Haddad FS, Brandao A, Peralta JM, Fernandes O. Genotyping of Giardia duodenalis from human and animal samples from Brazil using beta-giardin gene: a phylogenetic analysis. Acta Trop 2007; 102: 10-9.

[14] Solaymani-Mohammadi S, Singer SM. Giardia duodenalis: the double-edged sword of immune responses in giardiasis. Exp Parasitol 2010; 126: 292-7.

[15] Thompson RC, Monis PT. Variation in Giardia: implications for taxonomy and epidemiology. Adv Parasitol 2004; 58: 69-137.

[16] Amar CF, Dear PH, Pedraza-Diaz S, Looker N, Linnane E, McLauchlin J. Sensitive PCR-restriction fragment length polymorphism assay for detection and genotyping of Giardia duodenalis in human feces. J Clin Microbiol 2002; 40: 446-52.

[17] Radomyos P, Tangtrongchitr A, Krudsood S, Wilairatana P, Popruk S. Atlas of medical parasitology: with 465 colour illustrations. 8 ed. Bangkok: Medical media; 2010.

[18] Read CM, Monis PT, Thompson RC. Discrimination of all genotypes of Giardia duodenalis at the glutamate dehydrogenase locus using PCR-RFLP. Infect Genet Evol 2004; 4: 125-30.

[19] Sabchareon A, Chongsuphajaisiddhi T, Attanath P. Treatment of giardiasis in children with quinacrine, metronidazole, tinidazole and ornidazole. Southeast Asian J Trop Med Public Health 1980; 11: 280-4.

[20] Pengsaa K, Sirivichayakul C, Pojjaroen-anant C, Nimnual S, Wisetsing P. Albendazole treatment for Giardia intestinalis infections in school children. Southeast Asian J Trop Med Public Health 1999; 30: 78-83.

[21] Nuchprayoon S, Siriyasatien P, Kraivichian K, Porksakorn C, Nuchprayoon I. Prevalence of parasitic infections among Thai patients at the King Chulalongkorn Memorial Hospital, Bangkok, Thailand. J Med Assoc Thai 2002; 85: S415-23.

[22] Pikiewicz-Koch A. The frequency of giardiasis in various children's environment. Przegl Epidemiol 1999; 53: 339-43.

[23] Wongjindanon N, Suksrichavalit T, Subsutti W, Sarachart T, Worapisuttiwong U, Norramatha P. Current infection rate of Giardia lamblia in two provinces of Thailand. Southeast Asian J Trop Med Public Health 2005; $36: 21-5$.

[24] Thompson RC. The zoonotic significance and molecular epidemiology of Giardia and giardiasis. Vet Parasitol 2004; 126: 15-35.

[25] Abdel-Moneim SM, Sultan DM. Genetic characterization of Giardia lamblia isolates from Egyptian patients with relation to clinical giardiasis. J Egypt Soc Parasitol 2008; 38: 547-60.

[26] Haque R, Mondal D, Karim A, et al. Prospective case-control study of the association between common enteric protozoal parasites and diarrhea in Bangladesh. Clin Infect Dis 2009; 48: 1191-7.

[27] Perez CG, Cordova PSO, Vargas VF, et al. Prevalence of enteroparasites and genotyping of Giardia lamblia in Peruvian children. Parasitol Res 2008; 103: 459-65. 
[28] Sahagun J, Clavel A, Goni P, et al. Correlation between the presence of symptoms and the Giardia duodenalis genotype. Eur J Clin Microbiol Infect Dis 2008; 27: 81-3.

[29] Al-Mohammed HI. Genotypes of Giardia intestinalis clinical isolates of gastrointestinal symptomatic and asymptomatic Saudi children. Parasitol Res 2011; 108(6): 1375-81.

[30] Pelayo L, Nunez FA, Rojas L, et al. Giardia infections in Cuban children: the genotypes circulating in a rural population. Ann Trop Med Parasitol 2008; 102: 585-95.
[31] Nantavisai K, Mungthin M, Tan-ariya P, Rangsin R, Naaglor T, Leelayoova S. Evaluation of the sensitivities of DNA extraction and PCR methods for detection of Giardia duodenalis in stool specimens. J Clin Microbiol 2007; 45: 581-3.

[32] Ratanapo S, Mungthin M, Soontrapa S, et al. Multiple modes of transmission of giardiasis in primary schoolchildren of a rural community, Thailand. Am J Trop Med Hyg 2008; 78: 611-5.

(C) Popruk et al.; Licensee Bentham Open.

This is an open access article licensed under the terms of the Creative Commons Attribution Non-Commercial License (http://creativecommons.org/licenses/by$\mathrm{nc} / 3.0 /$ ), which permits unrestricted, non-commercial use, distribution and reproduction in any medium, provided the work is properly cited. 